\title{
Ethical Guidelines of the Alzheimer Society of Canada
}

\author{
John D. Fisk, A. Dessa Sadovnick, Carole A. Cohen, Serge Gauthier, \\ John Dossetor, Astrid Eberhart and Linda LeDuc
}

\begin{abstract}
Alzheimer's disease raises numerous ethical issues which vary and evolve over the course of the illness. In recognition of the need for ongoing discussion of these issues, the Alzheimer Society of Canada established a Task Force on Ethics in 1995. Through a process of "discourse ethics" and consultation on a national scale, the Task Force produced a series of guidelines dealing with the issues of: communicating the diagnosis, driving, respecting individual choice, quality of life, participation in research, genetic testing, the use of restraints, and end-of-life care. This manuscript presents a summary of these guidelines as well as a summary of the ideas on which they were based. It was the hope of the Society that the publication of these guidelines will serve to facilitate discussion of the ethics of care of those with Alzheimer's disease.
\end{abstract}

\begin{abstract}
RÉSUMÉ: Lignes directrices éthiques de la Société Alzheimer du Canada. La maladie d'Alzheimer soulève de nombreuses questions éthiques qui varient et évoluent au cours de la maladie. Reconnaissant la nécessité d'une discussion ininterrompue sur ces questions, la Société Alzheimer du Canada a établi un groupe de travail sur l'éthique en 1995. Par un processus de dissertation éthique et de consultation à l'échelle nationale, le groupe de travail a produit une série de lignes directrices concernant la communication du diagnostic, la conduite automobile, le respect de la volonté de l'individu, la qualité de vie, la participation à la recherche, les tests génétiques, l'utilisation de la contention et les soins en fin de vie. Ce manuscrit présente un sommaire de ces lignes directrices ainsi qu'un sommaire des idées sur lesquelles elles s'appuient. La Société espère que la publication de ces lignes directrices facilitera la discussion de l'éthique des soins aux patients atteints de la maladie d'Alzheimer.
\end{abstract}

Can. J. Neurol. Sci. 1998; 25: 242-248

The progressive decline in cognitive abilities and physical functioning that characterize Alzheimer's disease raises numerous ethical issues which vary and evolve throughout the course of the illness. These issues are faced by the affected individuals, their families, care providers, those who conduct research on Alzheimer's disease and society in general. In recognition of the need to facilitate open discussion of these issues, the Alzheimer Society of Canada established a Task Force on Ethics in 1995. In part, the establishment of this Task Force was a response to the call for feedback on early drafts of the "Code of Ethical Conduct for Research Involving Humans" circulated by the TriCouncil Working Group,' which were intended to supplant the existing Canadian guidelines for research involving human subjects. In preparing a response to these drafts, the Research Policy Committee of the Alzheimer Society identified the urgent need to address many other ethical issues. The Research Policy Committee made a recommendation to the Board of Directors to establish a Task Force on Ethics which was approved in April, 1995. During the process of establishing this Task Force, the Alzheimer Society became aware of the work of Dr. Stephen Post and Dr. Peter Whitehouse which had lead to the publication of the "Fairhill Guidelines". 2 These guidelines had been developed through a process of "discourse ethics" 3 which involved focus group discussions with family caregivers, individuals with "mild" AD, and professionals such as physicians, nurses, lawyers, ethicists and administrators. Following discussions with Drs. Post and Whitehouse and observations of this consultative process, staff of the Alzheimer Society agreed to build on the achievements of the Fairhill Guidelines by including a broader consultative process on a national scale. The first workshop of the Task Force took place in March, 1996 and the resultant draft guidelines were presented at the April, 1996 Annual Conference of the Alzheimer Society of Canada. This was the beginning of an extensive nationwide consultation process. An initial draft of the proposed guidelines was distributed across Canada via Alzheimer Society provincial organizations and chapters and other relevant organizations along with suggestions as to how to provide feedback. Two hundred and eleven responses were received. The issues which received the greatest attention and which resulted in the greatest divergence of

From the Departments of Psychology, Psychiatry and Medicine, Dalhousie University, Halifax (J.D.F.); Department of Medical Genetics, University of British Columbia, Vancouver (A.D.S.); Department of Psychiatry, University of Toronto, Toronto (C.A.C.); McGill Centre for Studies in Aging, McGill University, Montreal (S.G.); Bioethics Centre, University of Alberta and Capital Health, Edmonton (J.D.); Alzheimer Society of Canada (A.E., L.L.).

Reprint requests to: John D. Fisk, Alzheimer Society of Canada, 20 Eglinton Avenue West, Suite 1200, Toronto, Ontario, Canada M4R 1 K8 
opinion were communicating the diagnosis and driving. All of the responses were summarized and distributed to the Task Force members. These were discussed at a second workshop in December, 1996 and many suggestions were incorporated into the final draft of the guidelines. This document was presented to and approved by the Board of Directors in February, 1997 and made available to the public at the Annual General Meeting of the Alzheimer Society of Canada in April, 1997.4 The details of this process have been described in detail elsewhere. ${ }^{5}$ In this manuscript, the consensus opinions generated by this process and their bases are presented.

\section{Communicating the Diagnosis}

Affected individuals and their families should be informed about the diagnosis and directed to appropriate support services in a sensitive manner.

For many physicians, communicating the diagnosis of Alzheimer's disease or other neurodegenerative dementias can be one of their most difficult tasks. Even in the context of specialized dementia clinics, this task can be exceedingly difficult. Relations between family members can play a significant role as some may not want to have the diagnosis communicated to the affected individual while others do. As a result, physicians may find themselves in situations of conflict. The issue of communication of the diagnosis was raised in the Fairhill Guidelines because of concerns that affected individuals are not always informed of their diagnosis despite having a "moral and legal right ... to receive a specific diagnosis unless he or she waives it"2(p.1423).

The arguments that have been put forth against diagnostic disclosure are based on: the lack of absolute diagnostic certainty from clinical data, the absence of effective treatments of progressive dementias, the potential for adverse psychological responses to diagnostic disclosure, and the questionable ability of persons with more advanced disease to understand the implications of the diagnosis. ${ }^{6}$ Diagnostic uncertainty in Alzheimer's disease continues to exist despite significant improvements in diagnostic accuracy, and some uncertainty will likely continue to exist. Although numerous factors can contribute to the variable estimates of diagnostic sensitivity and specificity for the most commonly used diagnostic criteria, ${ }^{7,8}$ the consistency of a diagnosis of a progressive dementia over time is generally accepted as being high when based on a thorough examination. ${ }^{9}$ As in all neurodegenerative disorders, acquiring sufficient clinical information to establish a diagnosis of clinically probable Alzheimer's disease may require reassessment and the passage of time in order to establish a clear history of progression. Regardless of the absence of absolute diagnostic certainty, one cannot avoid the responsibility of providing individuals with "an open, honest presentation of information as it is perceived and known"6(p.949) at all stages of the assessment process.

Although the absence of effective treatments has been raised as an argument for failure to disclose the diagnosis in Alzheimer's disease, this situation is unlikely to exist within the very near future. Regardless of the availability of symptomatic treatments for Alzheimer's disease itself, the comprehensive management of the numerous medical, psychological and social issues that arise in the care of the person with dementia requires an open discussion of the diagnosis. One cannot justify failure to disclose a diagnosis of Alzheimer's disease on the grounds of the lack of appropriate interventions.
While concerns about the adverse psychological reactions to the disclosure of a diagnosis of Alzheimer's disease are valid, they do not justify a failure to disclose the diagnosis. Rather, they point out the need to be sensitive to each individual's situation. This includes consideration of his/her cognitive abilities, insight into his/her condition, current and past psychological state, and the available social support. Although cognitive impairments may be of such severity as to preclude the individual with Alzheimer's disease from fully appreciating the consequences of his/her diagnosis, this does not mean that they will receive no benefit from its disclosure. Disclosure to affected individuals in the presence of their family may also provide the family with an opportunity to see the individual as a person who is still respected by health care providers and assist all parties in discussing the diagnosis and its consequences openly. When Erde and colleagues ${ }^{10}$ asked individuals waiting to see their family physicians whether they would wish to know of their diagnosis if affected by dementia, over $90 \%$ indicated that they would. The most often cited reason was to plan financial and personal care issues in advance.

In their survey of the manner in which diagnoses were disclosed within 20 dementia clinics in the United Kingdom and Ireland, Gilliard and Gwilliam"1 reported that while virtually all clinics ensured disclosure to the affected individual and his/her family, the procedure by which this took place was flexible. Although such flexibility should be encouraged, the Task Force felt it necessary to outline some guiding principles to be considered. Identification of the family members who should be involved in the diagnostic disclosure early in the assessment process was recommended as was discussion of the diagnostic and disclosure process with them. Other principles include: ensuring involvement of those members of the health care team who can make important contributions to the disclosure process, ensuring that sufficient time is available for the disclosure process, considering the possibility of follow-up sessions to address unresolved issues, and discussion of the availability of support services.

\section{Driving}

Throughout the course of the disease, the person's driving ability needs to be monitored collaboratively by family members, physicians and/or other health care professionals. It is vital that all those involved in this process of monitoring communicate with one another. When the persons's driving is recognized as dangerous, automobile access must be removed immediately.

Driving an automobile is a complex activity which requires adequate eyesight, hearing, motor ability, judgment, the ability to respond quickly and an understanding and recall of the rules of the road. Although eventually a person with Alzheimer's disease must stop driving, the diagnosis does not automatically mean that the individual is incapable of driving safely. Furthermore, the rate of declining abilities can vary between individuals and there is no precise test that indicates when a person is no longer capable of driving safely. Thus, driving privileges become a particularly difficult ethical issue for individuals diagnosed in the early stages of the disease. Laboratory measures of cognitive abilities relevant to driving, such as shifting attention, typically reveal deficits in even mildly affected individuals. ${ }^{12}$ However, the risk of automobile accidents for persons with 
Alzheimer's disease has been found to be no different than that for age-matched controls ${ }^{13}$ and is lower than that for young adult males. ${ }^{2}$ Thus, after considerable discussion of this issue and the widely divergent opinions expressed in the comments to initial drafts of the guidelines, the Task Force was unable to derive specific practice guidelines. In acknowledging the complexities of this issue and the unique manner in which they present, the Task Force recommended a coordinated and individualized assessment process which involves the individual and his/her family in an open dialogue of this issue with physicians and other relevant health care providers. Similar recommendations have also been put forth recently by an expert panel convened by the Swedish National Road Administration. ${ }^{14}$ This process may often suffice for decision-making regarding driving safety. Specialized "road-tests" may make a significant contribution to understanding driving competence in drivers with mild dementia ${ }^{15.16}$ but, as with mandatory reporting to licensing authorities, road-testing is controversial..$^{14}$

Acceptance of restricted driving privileges is often difficult and requires a thoughtful approach on the part of physicians and other health care providers. ${ }^{17}$ Acceptance may be facilitated by using a gradual, negotiated approach to the implementation of driving restrictions whenever possible. The loss of independence that accompanies a loss of driving privileges must be minimized by the provision of alternatives to driving and assurances that family members and either formal or informal support services will continue to provide access to meaningful activities. As with diagnostic disclosure, the potential negative emotional reactions to the loss of driving privileges makes this issue difficult to address and can produce threats to the therapeutic alliance between the individual and his/her health care providers. Nevertheless, in some provinces, physicians have a legal responsibility to report to a licensing authority if they are of the opinion that an individual is not fit to drive, and in all cases where driving is considered dangerous, the need to protect public safety requires the removal of driving privileges. The issue of driving privileges is one that must typically be dealt with in the early stage of Alzheimer's disease. More recent studies have shown that the majority of individuals with Alzheimer's disease cease driving within a few years of diagnosis. ${ }^{13.18}$ As Trobe and colleagues ${ }^{13}$ noted, persons with Alzheimer's disease rarely decide to cease driving because of intervention by licencing bodies. The overwhelming majority of these decisions are made on the advice of family and/or physicians. Such findings serve to reinforce the approach to this issue advocated by the Task Force.

\section{Decisions: Respecting Individual Choice}

While still capable, the individual should be given choices and the opportunity to make decisions. Ideally, the individual has planned for the time when he/she can no longer make decisions and has identified another individual(s) who will take his/her prior wishes into consideration.

In societies which value personal autonomy, the ability to make decisions affecting one's life are extremely important to one's sense of self-worth and self-esteem. Although the progressive deterioration of cognitive functioning that characterizes Alzheimer's disease means that affected individuals eventually are unable to make appropriate decisions, the diagnosis of Alzheimer's disease alone does not preclude appropriate deci- sion-making. Across the country, the assessment of competency and/or an individual's decision-making capacity is governed by differing provincial laws and it is important to distinguish between legal status and clinical opinion. Even when standardized assessment approaches are used, clinical opinion regarding competency to consent to treatment can vary between physicians. ${ }^{19}$ Laws regarding designation of a substitute decisionmaker also vary across/between provinces. Throughout most of the disease process, some capacity for decision-making remains. This capacity varies with the nature of the decisions which fall on a continuum from simple expressions of immediate desire (e.g., rice or potatoes for dinner) to complex issues requiring comprehension of detailed information, specific experience and/or personal judgment (e.g., yes or no to the initiation of tube feeding). Those who provide care and assistance to individuals with Alzheimer's disease need to respect the decision-making capacity that remains and provide opportunities for the individual to make as many decisions as possible. Techniques to facilitate this process include reducing the number of options presented and reducing more complex decisions into a series of simple decisions (with step-by-step guidance through the stages).

Early diagnosis provides the individual with Alzheimer's disease the opportunity to discuss his/her opinions and wishes about complex issues with those who may ultimately be called upon to make these decisions (i.e., family members, substitute decision-makers, health care professionals). Ideally, these opinions and wishes will have been documented as advance directives and a person(s) will have been named who will make decisions that are not discussed explicitly in the advance directive. The presence of cognitive impairment may still allow an individual to complete an advance directive ${ }^{20}$ and it has been recommended that neurologists encourage individuals in the early stages of dementia to complete advance directives. ${ }^{21}$ One outcome of the deliberations of the second Ethics Task Force workshop was the identification of the importance of promoting the development of an advance directive "package" for persons with Alzheimer's disease and their families and work on this issue has begun. ${ }^{22}$

\section{Quality of Life}

Individuals with Alzheimer's disease are able to find pleasure and to experience satisfaction. The disease does not remove the ability to appreciate and respond, nor the ability to experience feelings such as anger, fear, joy, love or sadness.

Although the term "quality of life" receives considerable popular use, it is not a term which is easily defined. ${ }^{23}$ Quality of life is a concept that incorporates external observations and an individual's subjective opinions. It may focus on specific healthrelated issues ${ }^{24}$ or may include almost every aspect of one's life. Alzheimer's disease results in the eventual erosion of most aspects of one's quality of life. Understanding the affected individual's quality of life is difficult because cognitive impairments limit the ability of others to obtain accurate impressions of the individual's subjective experience. Knowledge of the person's past experiences, their current abilities, and the people, objects and occupations which provided meaning and satisfaction in the past, should all be used to guide decisions affecting their quality of life. Since health is central to a good quality of life it is essential that the overall health of the individual with Alzheimer's 
disease is monitored and treated effectively. This can be a particularly difficult clinical issue since atypical disease presentations are common among the elderly. ${ }^{25}$

Provision of supportive social and physical environments is also essential for preserving quality of life. Living spaces should be safe and secure and allow the individual to make use of his/her remaining abilities. Creative methods of drawing on the remaining abilities of the individual can enhance quality of life. The need for companionship and physical intimacy must be acknowledged and respected also, and relationships with family and friends should be fostered. The quality of life of the person with Alzheimer's disease will be affected by that of the caregiver(s). This may be most obvious in the relationship between caregiver "burden" and decisions to place a cognitively impaired family member in a long term care institution. ${ }^{26}$ However, it can also be inferred from the reduced social networks of caregivers, ${ }^{27}$ which must ultimately result in reduced opportunities for the person with Alzheimer's disease to engage in meaningful activities.

\section{Participation in Research}

Individuals with Alzheimer's disease at any stage, should have the opportunity to participate in research and their desires should be primary when considering participation in research. When the individual is no longer able to provide informed consent and the decision regarding participation is made by a substitute decision-maker, the research team has an obligation to ensure that the decision has been guided by the individual's wishes and/or that it has been made with the individual's best interests in mind. The research team must maintain an ongoing dialogue with the individual (e.g., re-affirmation of consent/assent), his/her family, and care providers. Participation of individuals with Alzheimer's disease in research often places demands on their family and care providers. All such individuals should be involved in the consent process and in the assessment of the consequences of participation.

The concept of free and fully informed consent, while a central principle of research ethics, poses problems when one considers the conduct of research on Alzheimer's disease. Recently, the majority of research conducted in Canada on Alzheimer's disease has been in accordance with the "Guidelines on Research Involving Human Subjects" published by the Medical Research Council of Canada. ${ }^{28}$ However, the ethical problems associated with research on Alzheimer's disease have received considerably more attention in the "Code of Ethical Conduct for Research Involving Humans"1 which will soon supplant the 1987 MRC guidelines and which draws attention to the importance of the principle of justice and the need to ensure that the potential to benefit from the participation in research is not denied to particular groups of individuals. As stated by High and colleagues, ${ }^{29}$ "To deny persons access to research participation out of fear of exploitation of specific groups of persons is to avoid rather than accept and practice ethical responsibility." (p. 68 ). The "code of ethical conduct" clarifies the issue of free and informed consent thus: "Competence in choosing to participate does not require that prospective participants be competent for every kind of choice but, rather, that they be competent for making an informed choice regarding participation in a research project."' (p.I-2). In recognition of this position, the Task Force felt that research protocols should include a method of determining the ability of the research subject to understand the nature of the research, the consequences of participation, and alternative choices. The need for standardized methods to determine capacity to provide informed consent has been pointed out by Marson and colleagues. ${ }^{30}$ Attempts to address the issue of standardized assessment of competency have been made in the context of advance directives ${ }^{20}$ but this remains controversial. ${ }^{29}$

In Canada, legislation regarding substitute decision-making for the participation of incompetent individuals in research varies among provinces and is often unclear. Most often, however, it is the family member(s) of the person with Alzheimer's disease who provide "third party authorization" as is the case for many decisions about clinical care. Nevertheless, it is incumbent upon the research team to ensure that decisions about participation in research that are made by a third party are in accord with the individual's wishes and are in his/her best interest. ${ }^{1,29}$ The use of advance directives for research participation have been promoted by some, ${ }^{31}$ while others have expressed concerns about their use. ${ }^{32}$ However, most would agree that advance directives can make an important contribution to the proxy consent process. ${ }^{32}$ Regardless of authorization of consent from a third party, the assent of the individual subject is almost invariably required for research to take place. ${ }^{1}$

The other major issue regarding the conduct of research in Alzheimer's disease with incompetent individuals is the assessment of risks versus benefits. As stated by High and colleagues: "No clear consensus exists either in the literature or in regulatory guidelines as to what constitutes an acceptable degree of risk when cognitively impaired persons are involved in research." (p.72). Careful consideration of the risks and benefits of research is essential in evaluating the ethical acceptability of any study which relies on proxy consent. Although there seems to be consensus that "risks beyond the threshold for normally acceptable risk"l or "risk of harm beyond a minor increment over minimal" 31 are not acceptable, such definitions are vague and remain open to the interpretation of local ethics review boards. Even for competent individuals with Alzheimer's disease, the process of informed consent should most often include the family member(s) since many study protocols assume that families will participate in important aspects of the protocol such as: providing transportation for the subject, providing observations of the subject's behaviour, monitoring medications, and implementing behavioural management strategies.

\section{Genetic Testing and Alzheimer's Disease}

The field of genetics is growing at an unprecedented pace. Nevertheless, at this time, for the vast majority of individuals, there is no test (genetic or non-genetic) to determine if a specific unaffected individual will develop Alzheimer's disease. Even for the very rare individual for whom it is possible to predict the future development of Alzheimer's disease based on genetic status, the decision to know or not know is a personal one which must be made in a setting that allows for informed consent, genetic and psychological counselling, and confidentiality.

Genetic advances are happening at an unimaginable pace, ${ }^{33}$ making it extremely difficult for health care professionals to stay informed of the most recent developments. Thus, it is understandable that there is much confusion about whether or 
not genetic tests can determine with certainty if an individual will develop Alzheimer's disease in the future. In discussing the genetics of Alzheimer's disease it is important to distinguish between predictive genetic testing and genetic risk assessment. Predictive genetic testing refers to identification of inherited (genetic) material in an unaffected individual which can identify with a high degree of certainty (nothing is $100 \%$ ) whether or not the person will develop Alzheimer's disease in the future. At present, predictive testing can only be offered to individuals from a small number of families which are characterized by Alzheimer's disease with very early onset (usually well under the age of 60 ) and by a family history in which affected individuals pass the disease to approximately $50 \%$ of their male and female offspring. In these very rare families, a specific genetic change (mutation) travels through the family with the disease. ${ }^{34-36}$ These genetic changes can be shared by more than one family or can be specific to one family.

In contrast, genetic risk assessment is the identification of a genetic risk factor(s) which could potentially increase an unaffected individual's chance of developing Alzheimer's disease. The presence or absence of a genetic risk factor does not positively identify who will get Alzheimer's disease and who will not since Alzheimer's disease can exist in the absence of a genetic risk factor or fail to develop in the presence of a genetic risk factor. ${ }^{37.38}$

Among individuals unaffected by Alzheimer's disease, some may wish to know whether they will develop the disease in the future while others may not want to know. It is thus critical that a person concerned about developing Alzheimer's disease in the future receive accurate information specific to his/her family. A strong family history of dementia does not necessarily imply that genetic testing is appropriate. Eligibility and appropriateness of genetic testing can best be determined by health care professionals at clinical genetics and/or dementia clinics located throughout Canada.

In the rare cases where genetic testing (either predictive testing or risk assessment) is appropriate, it must only be done with the individual's informed consent, with his/her agreement to have counselling, and with the understanding that confidentiality will be maintained in accordance with current legal guidelines. Results of genetic tests, regardless of whether the risk is increased or decreased for the future development of the disease, can have major ethical, social, psychological and legal implications for the individual being tested as well as his/her family. The Task Force expressed concern about the potential for financial exploitation of individuals who are willing to buy any test that claims it can "tell the future", whether or not the test has been proven definitive. The potential negative effects of testing on employability and insurability are well recognized. ${ }^{39}$ Thus, counselling by trained professionals must be an integral part of the testing process and all testing must include the essential components of consent, counselling, and guaranteed confidentiality. ${ }^{40}$

\section{The Use of Restraints}

It is recommended that no restraints be used. The inappropriate use of restraints results in the individual with Alzheimer's disease losing those skills and abilities needed for daily activities. Once these skills and abilities have been lost, they are unlikely to be regained. Should there be special reasons for considering the use of restraints, the risks and benefits to the indi- vidual and those around them must be weighed. If the use of a restraint can be justified, it must be used for a very limited time only and must be accompanied by well defined goals and very close monitoring.

The behavioural changes that accompany Alzheimer's disease pose numerous challenges to caregivers and can result in behaviours which are considered dangerous for the affected individual and those around him/her. In these situations, the use of restraints is often considered. Anything which restricts or controls an individual's movements or behaviours can be considered a restraint. Restraints can take various forms and include: environmental restraints, which represent changes to the person's surrounding that create barriers or limit movement; physical restraints, which are typically items attached to the body to restrict movement; and chemical restraints, which are medications such as tranquilizers and sedatives, that modify or restrict behaviour. Regardless of diagnosis, the presence of cognitive impairment has been shown to be highly related to the use of restraints in nursing homes ${ }^{41}$ and this use of restraints is often inappropriate. For example, physical restraints continue to be used in a number of settings with elderly persons in an attempt to reduce falls despite the ineffectiveness of restraints for this purpose. ${ }^{4 l-43}$ Moreover, physical restraints have also been shown to precipitate delirium in elderly persons in acute care settings. ${ }^{44}$ However, some therapeutic interventions could also be construed as restraints. Examples of this include: a protected garden with free access to the inside in order to provide freedom to wander in a safe environment, the use of a lap belt to assist an individual to sit upright and thereby participate in a meaningful activity, and the short term use of a medication to control hallucinations which are disturbing to the individual (as opposed to being disturbing to the care providers). Thus, any generalized prohibition of the use of restraints would be inappropriate.

Frengley ${ }^{45}$ argues for kindness as a guiding principle in the practice of medical care and describes the use of physical restraints as an unkind act. He points out, however, that lack of education, as well as laws and financial considerations, can work against the implementation of the principle of kindness in the health care setting. Similar concerns about the influence of financial considerations have also been expressed by Schnelle. ${ }^{46}$ At present, considerable variability exists in the use of physical restraints in the care of the elderly, notably between the United States and Great Britain. ${ }^{41,43}$ Given the changing health care environment in Canada, we must be careful to avoid any obstructions to the provision of compassionate care to vulnerable persons.

The growing concern about the use of medications as chemical restraints, and the increased knowledge of appropriate pharmacologic management of behavioural disturbances in Alzheimer's disease, have prompted recent reviews of this topic. ${ }^{47}$ Because of their worrisome side effects and indiscriminant use in the past, guidelines for the use of psychotropic medications in nursing homes have been legislated in some jurisdictions such as the United States. Since the introduction of such legislation, psychotropic medication use has been slowly reduced. In recent years, there has been an attempt to systematically study the efficacy of medications for specific symptoms such as paranoia and hallucinations but our knowledge of the most appropriate pharmacologic treatment of behavioural disturbances in Alzheimer's disease remains limited. ${ }^{48}$ Current studies 
are looking at the potential benefits of discontinuing psychotropic medications in individuals who have been on them for extended periods of time. Increasingly, environmental and caregiver interventions for behavioural problems are being studied and it is these approaches, combined with the judicious use of medications, which will probably be the most effective approach to caring for individuals with Alzheimer's disease who have behavioural problems. ${ }^{49}$

Since Alzheimer's disease is a progressive neurodegenerative disorder, ongoing changes in the abilities and behaviours of the affected individual will continually pose new challenges to care providers. A key to providing care which does not require the use of restraints is proper education about Alzheimer's disease and knowledge about the underlying basis of the behavioural disorder. Understanding more about the disease process and its effects on behaviour can help care providers understand: why certain behaviours occur, how potential problems may be solved or avoided without resorting to restraints, and what behavioural changes can be anticipated in the future. The interactive exchange of information among health care professionals, the Alzheimer Society and families of affected individuals is perhaps the best source of such knowledge.

\section{End-of-Life Care}

Respect for the individual's expressed wishes and interests should guide all end-of-life care decisions. In the transition from life to death, the ultimate goal of care should be to provide comfort and dignity to the person towards achieving what the individual considers to be a "good death". What defines a good death differs from individual to individual. In planning a good death, individuals should take into consideration their cultural, religious, spiritual, and family values.

Although death is a natural part of life, the progressive degenerative nature of Alzheimer's disease raises unique ethical issues related to care at the end of life, particularly in regard to the use of life-prolonging treatments in individuals with endstage dementia. ${ }^{50}$ Many individuals with Alzheimer's disease die from complications of the disease, such as pneumonia, and treatment choices regarding the use of measures such as antibiotics, tube feeding, mechanical respirators, cardiopulmonary resuscitation, and surgery, are most often made by substitute decision-makers. ${ }^{51,52}$ Since these decisions may have to be made in the context of conflicting opinions from health care professionals and/or family members, the role of the substitute decision-maker can be exceedingly difficult. Some caregivers may feel anguish over the subjects of euthanasia and assisted suicide even though both of these are illegal in Canada. In the United States, the move toward managed health care has raised other issues and has led to a call for the measurement of the quality of end-of-life care, such that consumers can make informed decisions regarding their choice of health plans. ${ }^{53}$

The Task Force recommends that resolution of the ethical issues regarding end-of-life care should be accomplished through open discussion between the individual with Alzheimer's disease, while still able to make decisions regarding future care choices, and those who will ultimately serve as the substitute decisionmaker(s). Once such discussions have taken place, the individual's wishes should be recorded in an advance directive. The progressive decline in capacity to complete such advance directives in Alzheimer's disease, makes this a pressing issue. Where the direc- tions of an advance directive are clear, the care decisions should be guided by the individual's expressed wishes. Where there is still doubt, every effort should be made to reach a consensus between the wishes expressed in the advance directive, the wishes of the family, and the opinion of the attending physician by weighing the risks and benefits of the decision to the individual. In hopes of lessening the burden of these decisions, the Alzheimer Society of Canada is preparing a specific advance directive for different stages of Alzheimer's disease and related dementias which will address both the naming of proxy decision makers and the question of participation in research after capacity has been lost. Conflicts and disagreement are best avoided through early and continuing communication but, should they arise, clinical ethics consultants and ethics committees of health care institutions may be of some assistance in facilitating consensus.

\section{Comment}

The goal of the Alzheimer Society of Canada Task Force on Ethics was to raise awareness of those ethical issues that were identified as being of primary importance to persons with Alzheimer's disease, their families, and their care providers. Publication of these guidelines is seen as an opportunity to begin the discussion of these issues among all interested parties. As our knowledge about Alzheimer's disease increases and effective treatments become available, the issues discussed above will continue to evolve and new issues will arise. It is our hope that the current guidelines will serve as a starting point and will lead to ongoing discussions of the ethics of the provision of care to those with Alzheimer's disease and their families.

\section{ACKNOWLEDGEMENTS}

This project was supported by the Alzheimer Society of Canada and the Medical Research Council of Canada. The members of the Task Force on Ethics were: Dr. Carole Cohen, Dr. Bernard Dickens, Dr. John Dossetor, Ms. Marg Eisner, Dr. John Fisk, Dr. Serge Gauthier, Mr. Jack Jefferson, Ms. Barbara Moffatt, Dr. Stephen Post, Dr. A. Dessa Sadovnick, Ms. Cal Shell, Dr. Neil Stuart, and Dr. Peter Whitehouse. Alzheimer Society staff member support was provided by Ms. Astrid Eberhart, Ms. Linda LeDuc, and Ms. Ivy Lim-Carter.

To obtain a copy of "Tough Issues", please contact the Alzheimer Society of Canada, 20 Eglinton Avenue West, Suite 1200, Toronto, Ontario, Canada M4R IK8. Tel: (416) 488-8772; Fax: (416) 488-3778; or consult the Society Web site at www.alzheimer.ca.

\section{REFERENCES}

1. Tri-Council Working Group. Code of Ethical Conduct for Research Involving Humans. Ottawa: Minister of Supplies and Services Canada, 1997.

2. Post SG, Whitehouse PJ. Fairhill guidelines on ethics of the care of people with Alzheimer's disease: a clinical summary. J Am Ger Soc 1995; 43: 1423-1429.

3. Habermas J. Justification and Application: Remarks on Discourse Ethics. Cambridge, MA: MIT Press, 1993.

4. Alzheimer Society of Canada. Tough Issues: Ethical Guidlines of the Alzheimer Society of Canada. Toronto: Alzheimer Society of Canada, 1997

5. Cohen CA, Whitehouse PJ, Post SG, et al. Ethical issues in Alzheimer's disease: the experience of a national Alzheimer Society Task Force. Alz Dis Relat Disorder (in press).

6. Drickamer MA, Lachs MS. Should patients with Alzheimer's disease be told their diagnosis? N Engl J Med 1992; 326: 947-951. 
7. Leach J, Levy R. Reflections on the NINCDS/ADRDA criteria for the diagnosis of Alzheimer's disease. Int J Geriatr Psychiat 1994; 9: 173-179.

8. Blackler D, Albert MS, Bassett SS, et al. Reliability and validity of NINCDS-ADRDA criteria for Alzheimer's disease: the National Institute of Mental Health Genetics Initiative. Arch Neurol 1994; 51: 1198-1204.

9. Schofield PW, Tang M, Marder K, et al. Consistency of clinical diagnosis in a community-based longitudinal study of dementia and Alzheimer's disease. Neurology 1995; 45: 2159-2164.

10. Erde EL, Nadal EC, Scholl TO. On truth telling and the diagnosis of Alzheimer's disease. J Fam Prac 1988; 26: 401-406.

11. Gilliard J, Gwilliam C. Sharing the diagnosis: a survey of memory disorders clinics, their policies on informing people with dementia and their families, and the support they offer. Int J Geriatr Psychiat 1996; 11: 1001-1003.

12. Parasuraman R, Nestor PG. Attention and driving skills in aging and Alzheimer's disease. Human Factors 1991; 33: 539-557.

13. Trobe JD, Waller PF, Cook-Flannagan CA, Teshima SM, Bieliauskas LA. Crashes and violations among drivers with Alzheimer disease. Arch Neurol 1996; 53: 411-416.

14. Lundberg $\mathrm{C}$, Johansson $\mathrm{K}$, Ball $\mathrm{K}$, et al. Dementia and driving: an attempt at consensus. Alz Dis Relat Disorder 1997; 11: 28-37.

15. Dobbs A. Evaluating the driving competence of dementia patients. Alz Dis Relat Disorder 1997; 11(Suppl. 1): 8-12.

16. Hunt LA, Murphy CF, Carr D, et al. Reliability of the Washington University road test. Arch Neurol 1997; 54: 707-712.

17. Friedland RP. Strategies for driving cessation in Alzheimer disease. Alz Dis Relat Disorder 1997; 11 (Suppl. 1): 73-75.

18. Drachman DA, Swearer JM. and Collaborative Study Group. Driving and Alzheimer's disease: the risk of crashes. Neurology 1993; 43: 2448-2456.

19. Marson DC, McInturff B, Hawkins L, et al. Consistency of physician judgments of capacity to consent in mild Alzheimer's disease. J Am Geriatr Soc 1997; 45: 453-457.

20. Molloy DW, Siberfield M, Darzins P, et al. Measuring capacity to complete an advance directive. J Am Geriatr Soc 1996; 44: 660664.

21. The American Academy of Neurology Ethics and Humanities Subcommittee. Ethical issues in the management of the demented patient. Neurology 1996; 46: 1180-1183.

22. Dossetor JB, Fraser RS. Preserving dignity: the use of advance directives for decision-making in health care. Edmonton: The Bioethics Centre, University of Alberta, 1997.

23. Faden R, German PS. Quality of life: considerations in geriatrics. Clin Ethics 1994; 10: 541-551

24. Guyatt GH, Van Zanten SJO, Feeny DH, Patrick DL. Measuring quality of life in clinical trials: a taxonomy and review. Can Med Assoc J 1989; 140: 1441-1448.

25. Fried LP, Storer DJ, King DE, Lodder F. Diagnosis of illness presentation in the elderly. J Am Geriatr Soc 1991; 39: 117-123.

26. Zarit SH, Todd PA, Zarit JM. Subjective burden of husbands and wives as caregivers: a longitudinal study. Gerontologist 1986; 26: 260-266.

27. Morgan DL, March, SJ. The impact of life events on networks of personal relationships: a comparison of widowhood and caring for a spouse with Alzheimer's disease. J Soc Personal Relations 1992; 9: 563-584.

28. Medical Research Council of Canada. Guidelines on Research Involving Human Subjects. Ottawa: Minister of Supplies and Services Canada, 1987.

29. High DM, Whitehouse PJ, Post SJ, Berg L. Guidelines for addressing ethical and legal issues in Alzheimer disease research: a position paper. Alz Dis Relat Disorder 1994; 8: 66-74.
30. Marson DC, Schmitt FA, Ingram KK, Harrell LE. Determining the competency of Alzheimer patients to consent to treatment and research. Alz Dis Relat Disorder 1994; 8: 5-18.

31. Keyserlingk EW, Glass K, Kogan S, Gauthier S. Proposed guidelines for the participation of persons with dementia as research subjects. Perspectives Biol Med 1995; 38: 319-362.

32. Sachs GA. Advance consent for dementia research. Alz Dis Relat Disorder 1994; 8: 19-27.

33. Epstein CJ. 1996 ASHG Presidential Address: towards the $21 \mathrm{st}$ century. Am J Hum Genetics 1996; 60: 1-9.

34. Goate AM, Chartier-Harlin MC, Mullan M, et al. Segregation of a missense mutation in the amyloid precursor protein gene with familial Alzheimer's disease. Nature 1991; 349: 704-706.

35. St. George-Hyslop P, Haines J, Rogaev EI, et al. Genetic evidence for a novel familial Alzheimer's disease locus on chromosome 14. Nature Genetics 1992; 2: 330-334.

36. Levy-Lahad E, Wijsman EM, Nemens, et al. A familial Alzheimer's disease locus on chromosome 1. Science 1995; 269: 970-973.

37. American College of Medical Genetics/American Society of Human Genetics Working Group on ApoE and Alzheimer Disease. Statement on use of Apolipoprotein E testing for Alzheimer disease. J Am Med Assoc 1995; 274: 1627-1629.

38. Blacker D, Haines JL, Rodes L, et al. ApoE-4 and age at onset of Alzheimer's disease: the NIMH Genetics Initiative. Neurology 1997; 48: 139-147.

39. National Institute on Aging/Alzheimer's Association Working Group. Apolipoprotein E genotyping in Alzheimer's disease. Lancet 1996; 347: 1091-1095.

40. Merz JF. Is genetics research "minimal risk"? IRB 1996; 18: 7-8.

41. Capezutti E, Evans L, Strumpf N, Maislin G. Physical restraint use and falls in nursing home residents. J Am Geriatr Soc 1996; 44: 624-633.

42. Powell C, Mitchell-Pedersen L, Fingerote E, Edmund L. Freedom from restraint: consequences of reducing physical restraints in the management of the elderly. Can Med Assoc J 1989; 141: $561-564$

43. O'Keeffe S, Jack CIA, Lye M. Use of restraints and bedrails in a British hospital. J Am Geriatr Soc 1996; 44: 1086-1088.

44. Inouye SK, Charpentier PA. Percipitating factors for delirium in hospitalized elderly persons: predictive model and interrelationship with baseline variability. J Am Med Assoc 1996; 275: 852-857.

45. Frengley JD. The use of physical restraints and the absence of kindness. J Am Geriatr Soc 1996; 44: 1125-1127.

46. Schnelle JF, Smith RL. To use physical restraints or not? J Am Geriatr Soc 1996; 44: 727-728.

47. Herrmann N, Lanctot KL, Naranjo CA. Behavioural disorders in demented elderly patients: current issues in pharmacotherapy. CNS Drugs 1996; 6(4): 280-300.

48. Boroson S, Raskind MA. Clinical features and pharmacologic treatment of behavioural symptoms of Alzheimer's disease. Neurology 1997; 48(Suppl. 6): S17-S24.

49. Jarrett PG, Rockwood K, Mallery L. Behavioural problems in nursing home residents: safe ways to manage dementia. Postgrad Med 1995; 97: 189-196.

50. Sachs GA, Ahronheim JC, Volicer L, Lynn J. Good care of dying patients: the alternative to physician-assisted suicide and euthanasia. J Am Geriatr Soc 1995; 43: 553-562.

51. Emanuel EJ, Emanuel LL. Proxy decision making for incompetent patients: an ethical and empirical analysis. J Am Med Assoc 1992; 267: 2067-2071.

52. Lynn J. Procedures for making medical decisions for incompetent adults. J Am Med Assoc 1992; 267: 2082-2084.

53. American Geriatrics Society. Measuring quality of care at the end of life: a statement of principles. J Am Geriatr Soc 1997; 45: 526-527. 